\title{
O USO DE PRODUTOS ORBITAIS PARA A PARAMETRIZAÇÃO DE PROCESSOS FÍSICOS EM MODELOS NUMÉRICOS REGIONAIS E SUAS ALTERAÇÕES CLIMATOLÓGICAS
}

\author{
PEREIRA, Gabriel - pereira@ufsj.edu.br \\ DEGEO/UFS] \\ SILVA, Maria Elisa Siqueira - elisasiq@usp.br \\ FFLCH/USP \\ MORAES, Elisabete Caria - bete@dsr.inpe.br \\ DSR/INPE
}

\begin{abstract}
RESUMO. As propriedades físico-químicas e biológicas da superfície terrestre ocasionam alterações no balanço de energia, na precipitação, na umidade do ar, na temperatura do ar e, consequentemente, na circulação regional e global. Desta forma, as parametrizações físicas destas variáveis, assim como, a representação espacial de cada classe de uso e cobertura da terra compõem uma importante variável na modelagem numérica de sistemas terrestres. Neste contexto, os produtos orbitais estimados a partir de técnicas de Sensoriamento Remoto podem ser empregados para atualizar os dados de entrada de modelos atmosféricos, regionais ou globais, em que o uso e cobertura da terra, assim como, os parâmetros físico-químicos e biológicos estejam defasados em relação ao uso atual. Assim, o principal objetivo deste estudo é avaliar o impacto nas simulações numéricas do Regional Climate Model system versão 4 (RegCM4) derivadas da atualização dos parâmetros físico-químicos e biológicos utilizados pelo Biosphere Atmosphere Transfer Scheme (BATS) para as componentes meteorológicas: umidade relativa do ar, radiação solar incidente, precipitação e temperatura do ar a dois metros. Percebe-se que as maiores variações e erros encontrados nos parâmetros do modelo estão relacionados às áreas de Floresta Ombrófila Densa, regiões pantanosas e inundáveis, áreas agrícolas e de vegetação arbustiva perene. Nestas, o modelo BATS pode subestimar em até três vezes os valores encontrados para estes tipos de fitofisionomias para a América do Sul. Em geral, a substituição de áreas com vegetação arbórea e outros tipos de uso ocasionam uma diminuição da evapotranspiração, principalmente pela redução da transpiração vegetal nos meses de maior atividade convectiva, reduzindo o volume de chuvas e formação de nuvens, além de aumentar em até $2^{\circ} \mathrm{C}$ a temperatura do ar a dois metros.
\end{abstract}

Palavras-chave: Modelagem numérica, sensoriamento remoto, parâmetros físicos, RegCM4.

THE USE OF ORBITAL PRODUCTS TO PHYSICAL PROCESS PARAMETRIZATION IN REGIONAL NUMERICAL MODELS AND ITS CLIMATOLOGICAL VARIATIONS

ABSTRACT. The physical-chemical and biological characteristics of terrestrial surface cause changes in energy balance, in precipitation, in relative humidity of air, in air temperature, and, consequently, in the regional and global circulation. Thus, the physical parameterizations of these variables, as well as the spatial representation of each land use and land cover class are an important variable in the numerical modeling of terrestrial systems. In this context, the products estimated from orbital remote sensing techniques can be used to update the input data of atmospheric models, which land use and land cover, as well as the physical-chemical and biological properties, are outdated. Therefore, the main objective of this study is to evaluate the impact in Regional Climate Model version 4 (RegCM4) numerical simulations derived from physical-chemical and biological update used by Biosphere Atmosphere Transfer Scheme (BATS) for: humidity air, solar radiation, precipitation and air temperature at two meters. It is noticed that the largest variations and errors found in the model parameters are related to areas of rain forest, swampy and flooded area, agricultural areas and perennial shrub vegetation. Accordingly, the BATS model underestimated up to three times the values found for these types of South America vegetation. In general, the substitution of forest areas originates a reduction in evaporation, mainly by reducing plant transpiration during the months of highest convective activity, reducing rainfall and cloud formation, and increasing up to $2{ }^{\circ} \mathrm{C}$ the air temperature at two meters.

Keywords: Numerical modeling, remote sensing, physical parameters, RegCM4.

\section{INTRODUÇÃO}

Nos últimos séculos, com o advento da revolução industrial, as mudanças no uso e cobertura da terra sofreram uma constante aceleração devido à globalização dos mercados, à expansão populacional e ao aumento da capacidade tecnológica. A substituição da cobertura natural ao longo do tempo tem provocado a diminuição no número de indivíduos, extinção, domesticação e mudanças de habitat de várias espécies (MEYER e TURNER, 1994). Além disto, o desflorestamento, o uso de pastagens para criação de rebanhos, a expansão de áreas agrícolas e urbanas, a drenagem de áreas alagadas, entre outros usos, nunca se expandiram tão rapidamente em todo o mundo. Grande parte das áreas do globo sofrem algum tipo de manejo, os quais variam em diversos graus de intensidade (RICHARDS, 1990).

Estima-se que nos últimos três séculos aproximadamente 1200 milhões de hectares (Mha) de florestas e vegetação arbustiva foram derrubadas e 560 Mha de gramíneas e pastagens foram convertidas em outros usos e cobertura da terra. Neste mesmo período, as áreas agrícolas em todo o globo aumentaram aproximadamente 1200 Mha, passando de 265 Mha no século XVIII (RICHARDS, 1990) para aproximadamente 1500 Mha nos dias atuais (FAO, 2002). Estas mudanças afetam significativamente o tempo e o clima (NIYOGI et al., 2009), e têm recebido 
atenção especial nas últimas décadas devido ao seu papel na forçante radiativa global (MEARNS et al., 1995; MOLDERS e RUHAAK, 2002; SILVA et al., 2006).

As condições meteorológicas e o clima influenciam significativamente a vida e a distribuição de biomas pelo planeta. O sistema climático consiste de um sistema dinâmico formado por cinco componentes principais: a atmosfera, a hidrosfera, a criosfera, a litosfera e a biosfera. Estas componentes são influenciadas por diversos mecanismos externos, em que o Sol e as alterações antropogênicas são os mais importantes (BAEDE et al., 2001). A radiação solar absorvida pela superfície e a contrarradiação termal podem ser utilizadas para evaporar a água presente no solo, nas folhas de plantas e na hidrografia. Além disto, outro fator importante da superfície terrestre é a rugosidade, pois influencia na circulação dos ventos. A biosfera, composta por regiões marinhas e terrestres, influencia na composição atmosférica a partir do sequestro e liberação de gases do efeito estufa, bem como é primordial na liberação de água para a atmosfera. Logo, a biosfera tem um papel fundamental no ciclo da água e do carbono, assim como, em outros ciclos como o do $\mathrm{CH}_{4}$ e $\mathrm{NO}_{2}$. Ainda, a liberação de compostos orgânicos voláteis pela biosfera atua na física atmosférica, na formação de aerossóis, alterando, desta forma, a formação de nuvens e o clima (ISIDOROV et al., 1985)

Atualmente, encontram-se disponíveis vários produtos originados por diversos sensores orbitais que contém informações sobre o uso e cobertura da terra, como, por exemplo, o GLOBCOVER, o Global Land Cover 2000 (GLC2000) e o Moderate Resolution Imaging Spectroradiometer Land Cover Map (MODIS LC-I). A utilização do Sensoriamento Remoto proporciona uma fonte alternativa para produzir informações sobre o uso e cobertura da terra devido à visão sinótica e possibilidade de aquisição de informações em intervalos regulares e em várias escalas espaciais (XIE et al., 2008).

Ainda, o Sistema Global de Observação do Clima (do inglês, Global Climate Observing System - GCOS) identificou o uso e cobertura da terra como uma das variáveis climáticas que devem ser derivadas a partir de satélites ambientais, uma vez que métodos tradicionais (coleta de dados em campo, revisões bibliográficas e outros tipos de processamentos de dados) demandam um período de análise muito grande e com grandes custos operacionais (GCOS, 2006). Neste contexto, os produtos globais e regionais que permitem estimar o uso e a cobertura da superfície terrestre a partir de técnicas de Sensoriamento Remoto podem ser empregados para atualizar os dados de entrada de modelos atmosféricos, regionais ou globais, em que o uso e cobertura da terra esteja defasado em relação ao uso atual. Além disto, as imagens orbitais possibilitam a estimativa de diversos parâmetros físico-químicos e biológicos (reflectância in-band, radiação fotossinteticamente ativa) e índices (vigor vegetativo, área foliar, entre outros). Neste contexto, o principal objetivo deste estudo é avaliar o impacto nas simulações numéricas do RegCM4 derivadas da atualização dos parâmetros físico-químicos e biológicos utilizados pelo Biosphere Atmosphere Transfer Scheme (BATS) para as componentes meteorológicas: umidade relativa do ar, radiação solar incidente, precipitação e temperatura do ar a dois metros.

\section{MATERIAIS E MÉTODOS}

\section{Área de estudo e as simulações no RegCM4}

A área de estudo (Figura 1) compreende a parte central da América do Sul, localizada entre as coordenadas geográficas com latitudes entre $10^{\circ} \mathrm{N}$ e $40^{\circ} \mathrm{S}$, longitudes entre $95^{\circ} \mathrm{W}$ e $30^{\circ} \mathrm{W}$, e representa um recorte do domínio espacial utilizado nas simulações com o modelo RegCM. O RegCM4, modelo numérico de área limitada, é caracterizado pela boa consistência na representação das variáveis meteorológicas. No entanto, sua eficácia depende das condições iniciais e de contorno lateral provenientes de modelos globais que irão suprir as informações necessárias ao início dos processamentos. Para as simulações numéricas realizadas no RegCM4 definiu-se como resolução espacial o valor de $50 \mathrm{~km}^{2} \mathrm{com}$ início da grade em S $22^{\circ} 00^{\prime}$ e $\mathrm{O}$ 
$60^{\circ} 00^{\prime}$, correspondendo a 160 pontos na coordenada x (longitude), 160 pontos na coordenada y (latitude) e 18 níveis em z (altitude). Como condições iniciais e de contorno lateral e temperatura da superfície do mar (TSM) foram utilizados os dados provenientes do European Centre for Medium-Range Weather Forecasts (ECMWF) e a parametrização cúmulos de Emmanuel (1991).

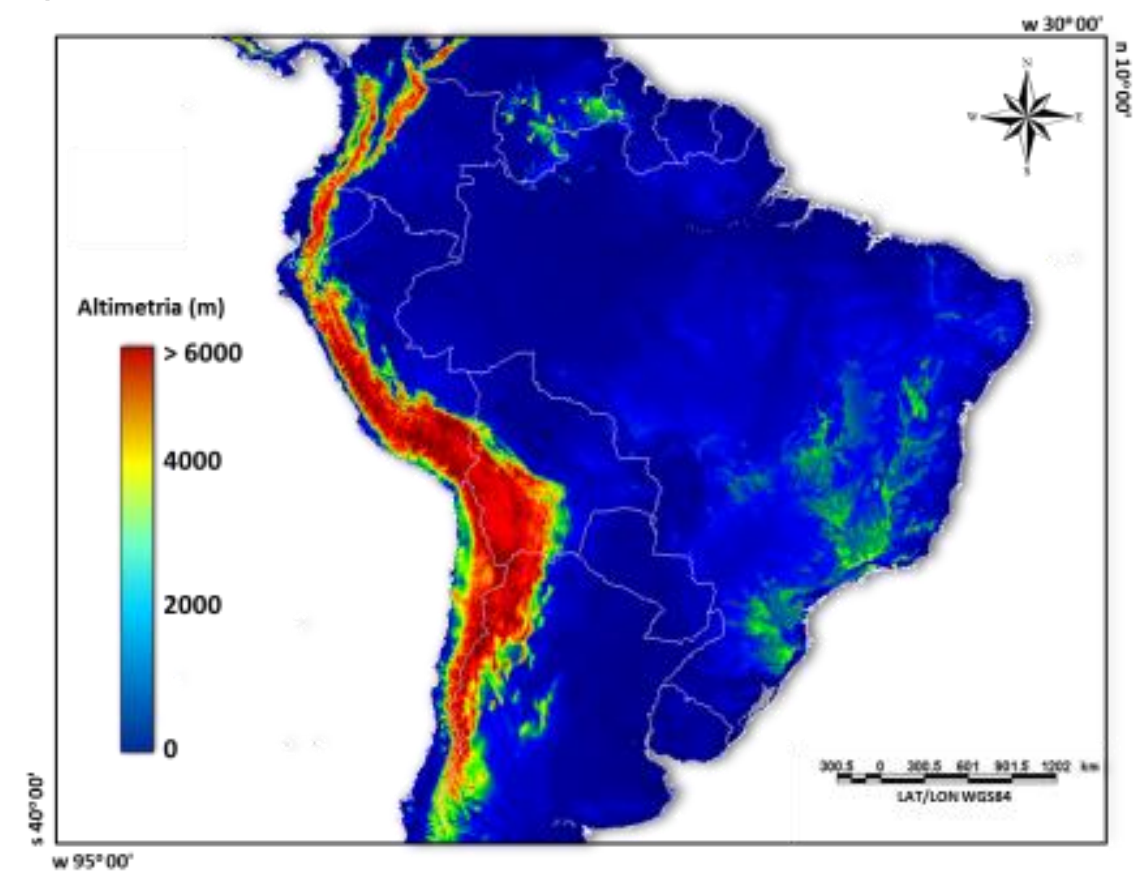

Figura 1. Localização da área de estudo e respectiva altimetria (m).

Materiais Utilizados para estimar as propriedades físico-químicas e biológicas da superfície terrestre

O sensor Moderate Resolution Imaging Spectroradiometer (MODIS) abordo dos satélites Terra/Aqua adquirem informações da superfície terrestre a partir de um ângulo de imageamento de aproximadamente $55^{\circ}$, altitude de $700 \mathrm{~km}$ e faixa imageada de $2330 \mathrm{~km}$. Estes sensores, com resolução espacial nominal que varia entre 250 - 10.000 metros, dependendo da região do espectro eletromagnético utilizada, adquirem informações aproximadamente duas vezes por dia (MODIS/TERRA - 10h30min e 22h30min; MODIS/AQUA $13 \mathrm{~h} 30 \mathrm{~min}$ e $01 \mathrm{~h} 30 \mathrm{~min}$ ) e recebem a sigla MOD, MYD e MCD para produtos originados pelos satélites TERRA, AQUA e ambos, respectivamente. Neste trabalho utilizaram-se os produtos de uso e cobertura da terra para a América do Sul, resolução espacial de 500×500m, anual, denominado MCD12Q1; índice de vegetação, resolução espacial de 5600x5600m, global e mensal (MOD13C2); índice de área foliar (IAF), resolução espacial de $1000 \times 1000 \mathrm{~m}$, a cada 8 dias (MCD15A2);e albedo da superfície, resolução espacial de 5600×5600m, global, a cada 16 dias (MCD43C3).

Além dos produtos das plataformas TERRA e AQUA, foram empregados dados de precipitação do Tropical Rainfall Measuring Mission (TRMM) para comparar as estimativas de precipitação originadas pelo modelo RegCM4. Os dados do TRMM referem-se ao produto 3B43 V6, com uma resolução temporal mensal, cobertura geográfica correspondente a $50^{\circ} \mathrm{S}$ a $50^{\circ} \mathrm{N}$ e resolução espacial de $0,25^{\circ} \times 0,25^{\circ}$. 
A Figura 2 exibe o fluxograma da metodologia separado por produtos utilizados, préprocessamento e análise dos resultados. A primeira etapa a ser realizada antes das simulações no RegCm4 é a aquisição dos dados de relevo, uso e cobertura da terra (UCT), condições iniciais e de contorno lateral. Neste trabalho, utilizaram-se os dados de uso e cobertura da terra do MODIS, com resolução de 250 metros, as reanálises do ECMWF e o relevo proveniente do produto GTOPO30 Terrain, com aproximadamente $4 \mathrm{~km}$ de resolução. Estes produtos são inseridos no modelo e a segunda etapa refere-se ao pré-processamento dos dados. Nesta etapa, os dados são convertidos para o formato do modelo e recortados para a área de estudo escolhida (Figura 1). A terceira etapa consistiu no processamento dos dados com as características físico-químicas e biológicas provenientes do sensor MODIS e na conversão do índice de vegetação por diferença normalizada (NDVI) em fração máxima de cobertura vegetal (Equação 1).

$$
\sigma_{v}=\frac{N D V I-N D V I_{s}}{N D V I_{v}-N D V I_{s}}
$$

em que $\mathrm{S}$ representa o valor de NDVI para o solo exposto e $\mathrm{V}$ o valor de NDVI para a vegetação. Neste estudo os valores de $\mathrm{NDVI}_{\mathrm{s}}$ e NDVI $\mathrm{N}_{v}$ foram, respectivamente, 0,05 e 0,94.

Embora alguns estudos indiquem que existe uma relação não-linear entre o NDVI e a fração de cobertura vegetal (CARLSON e RIPLEY, 1997), outros estudos propõem que a abordagem linear para estudos globais são adequados, devido principalmente, à falta de dados necessários à solução das equações não-lineares. Desta forma, a Equação 1 foi utilizada neste trabalho para determinar a fração máxima de cobertura vegetal a partir dos dados estimados pelo sensor MODIS/TERRA.
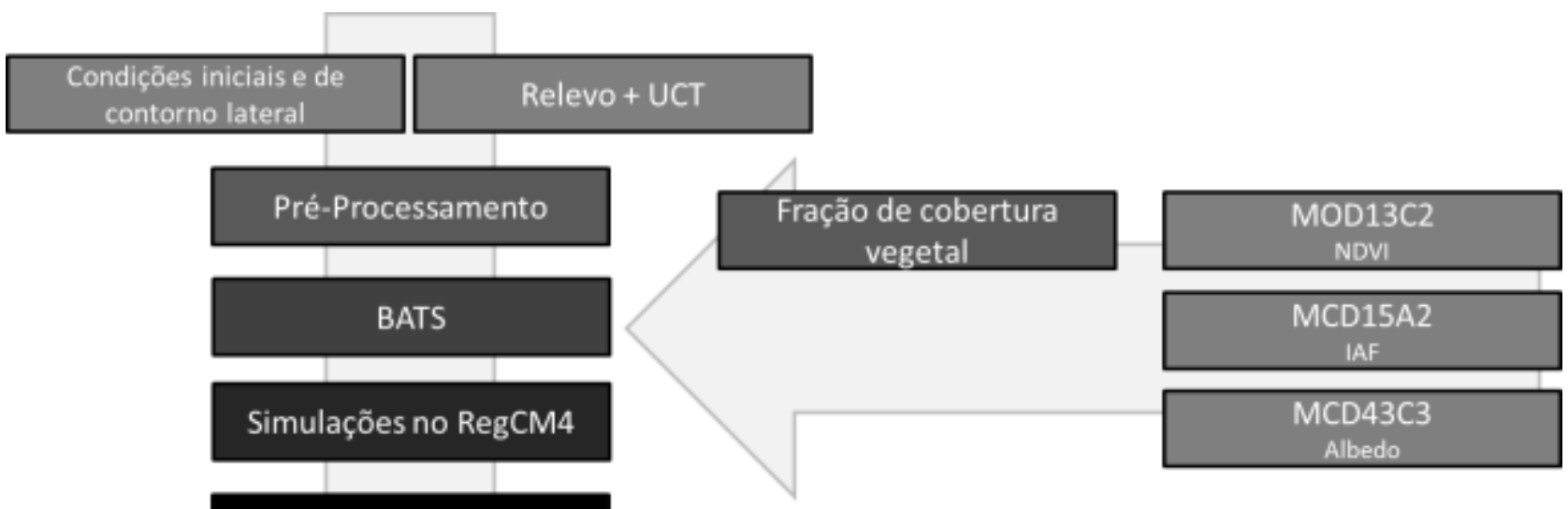

Análise dos Resultados

Figura 2. Fluxograma da metodologia.

A quarta etapa da metodologia consistiu na atualização dos valores de Fração de cobertura vegetal (FCV), reflectância no visível e no infravermelho próximo e médio (RVIVPM) e índice de área foliar (IAF) máximo e mínimo. A partir da atualização dos parâmetros mencionados anteriormente, definiu-se o tempo de simulação (01 de janeiro de 2000 a 01 de janeiro de 2010) e realizaram-se duas rodadas distintas: uma com o modelo RegCM4 sem alterações e outra alterando-se o UCT (Tabela 1) e os respectivos parâmetros físicos. A última etapa consistiu na análise dos resultados e comparação das mudanças de UCT e respectivas 
variações nas variáveis meteorológicas (umidade relativa do ar, radiação solar incidente, precipitação e temperatura do ar a dois metros).

Tabela 1 -Classes de uso e cobertura da terra utilizadas pelo BATS.

\begin{tabular}{l|l|l|l}
\hline $\mathbf{1}$ & Predominância Agrícola & $\mathbf{1 1}$ & Semideserto \\
\hline $\mathbf{2}$ & Gramíneas & $\mathbf{1 2}$ & Gelo / Glaciar \\
\hline $\mathbf{3}$ & Floresta de coníferas & $\mathbf{1 3}$ & Região Pantanosa / Alagada \\
\hline $\mathbf{4}$ & Floresta de coníferas decidual & $\mathbf{1 4}$ & Água interior \\
\hline $\mathbf{5}$ & Floresta Estacional Decidual & $\mathbf{1 5}$ & Oceano \\
\hline $\mathbf{6}$ & Floresta Ombrófila Densa & $\mathbf{1 6}$ & Vegetação arbustiva perene \\
\hline $\mathbf{7}$ & Vegetação Herbácea & $\mathbf{1 7}$ & Vegetação arbustiva decidual \\
\hline $\mathbf{8}$ & Deserto & $\mathbf{1 8}$ & Mosaico de Floresta e pastagem \\
\hline $\mathbf{9}$ & Tundra & $\mathbf{1 9}$ & Mosaico de pastagem e floresta \\
\hline $\mathbf{1 0}$ & Agricultura irrigada & $\mathbf{2 0}$ & Combinação de água e terra \\
\hline
\end{tabular}

\section{RESULTADOS E DISCUSSÃO}

\section{Parâmetros físicos utilizados pelo BATS}

A Figura 3 exibe os valores de IAF mínimo e máximo adotados pelo modelo RegCM4 e atualizados a partir dos dados orbitais do sensor MODIS (PEREIRA et al., 2013) para cada classe de UCT utilizada pelo modelo de superfície BATS (Tabela 1). Na Figura 3 os valores de IAF (adimensional) implementados e utilizados pelo modelo BATS são apresentados na cor cinza claro, os valores atualizados a partir dos produtos orbitais são exibidos em cinza escuro e a diferença (em proporção, \%) estão em preto no eixo secundário (eixo direito). Ainda, todos os valores são apresentados na tabela abaixo da área do gráfico. Entre os valores de IAF mínimo que apresentaram as maiores variações podem-se citar as classes 13 e 19 (com valores positivos) e $1,10,11$ e 16 (diminuição dos valores), que representam, respectivamente, áreas de região Pantanosa, mosaico de pastagem e floresta, predominância agrícola, agricultura irrigada, semideserto e vegetação arbustiva perene. 

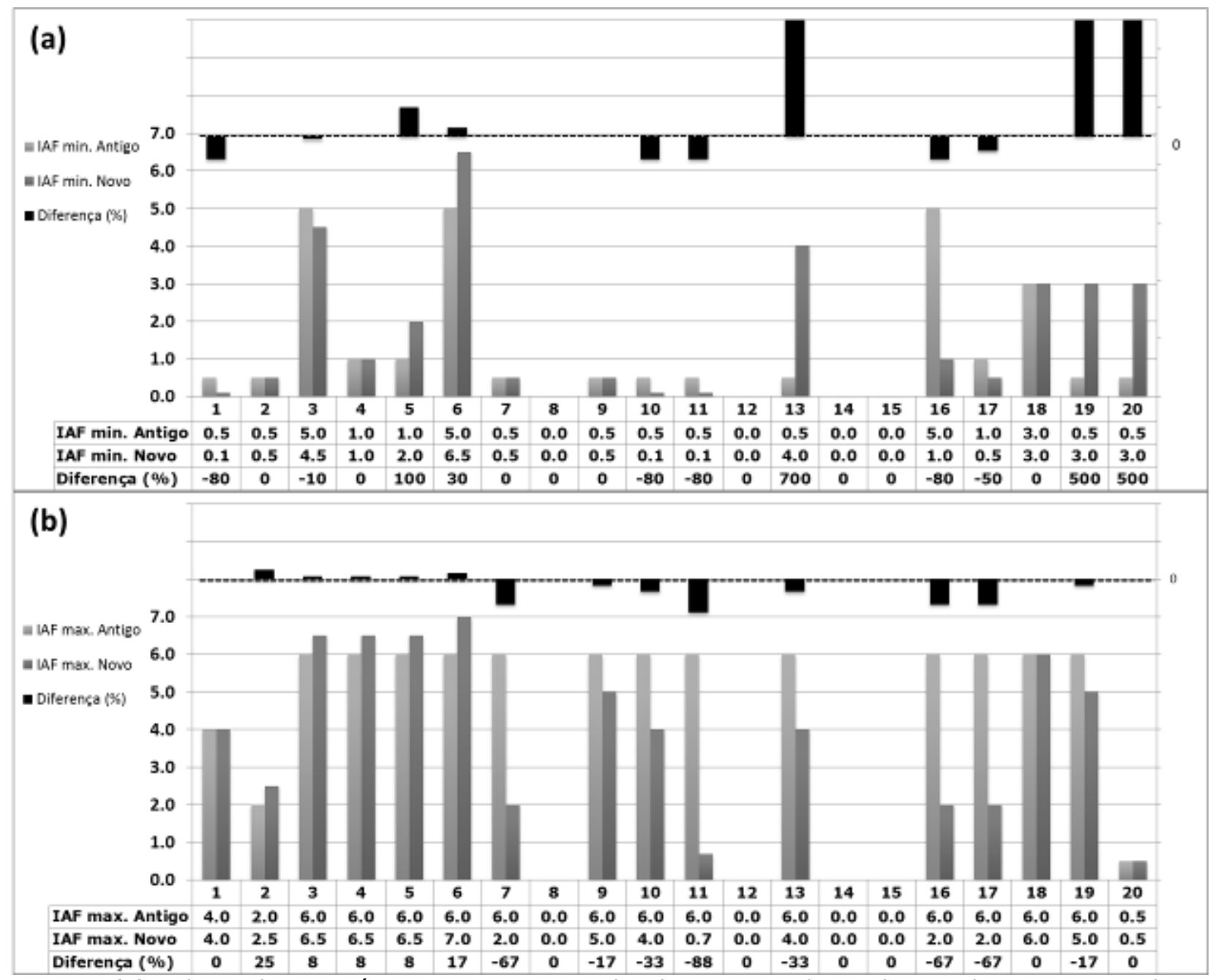

Figura 3. (a) Valores de IAF mínimos antigos e atualizados a partir de produtos orbitais para as classes de uso e cobertura da terra utilizadas pelo modelo de superfície BATS (Tabela 1); (b) Valores máximos de IAF antigos (padrão modelo) e atualizados, utilizados nas simulações numéricas.

Ainda, em relação aos valores de IAF máximo, as maiores variações foram encontradas nas classes 2 e 6 (aumento no IAF) e 7, 11, 16 e 17 (diminuição nos valores de IAF) compreendendo áreas com predominância de gramíneas, floresta ombrófila densa, vegetação herbácea, semideserto, vegetação arbustiva perene e vegetação arbustiva decidual, respectivamente. A partir das diferenças encontradas entre os valores atualizados e utilizados pelo BATS, pode-se dizer que as maiores diferenças são encontradas em formações florestais. Este fato explica-se pelo fato que o modelo RegCM4 é utilizado para modelagens climáticas globais, desta forma, os valores físicos compreendem uma média de todas as fitofisionomias similares no globo.

Assim como visualizado na figura acima, a Figura 4 exibe os gráficos da fração máxima de cobertura vegetal, expresso por FCV (\%), com os valores adotados pelo BATS e atualizados a partir do NDVI estimado pelo sensor MODIS/TERRA (Figura 4a) e da reflectância fotossinteticamente ativa (PAR, adimensional) que compreende uma média da reflectância espectral referente aos comprimentos de onda 0,4 a 0,7 $\mu \mathrm{m}$, utilizado pelas plantas no processo de fotossíntese a partir dos pigmentos da folha (clorofila, carotenoide, xantofilas) eatuam como absorvedores da radiação eletromagnética nesta região espectral (Figura 4b). Ainda, a Figura 4c exibe o gráfico com os valores de reflectância no infravermelho (IV) solar $(0,7$ a 4,0 $\mu \mathrm{m}$, aproximadamente), referentes aos processos que ocorrem na estrutura celular e ao conteúdo de água no interior das folhas. Ressalta-se que algumas componentes das folhas são praticamente transparentes à radiação eletromagnética (REM) na região do 
infravermelho como, por exemplo, a epiderme e a cutícula. Entretanto, ao incidir nas células do mesófilo esponjoso e nas cavidades de ar presentes no interior da folha, a REM sofre múltiplos espalhamentos e refração (devido à diferença de meios), aumentando, desta forma, a reflectância nesta faixa espectral.

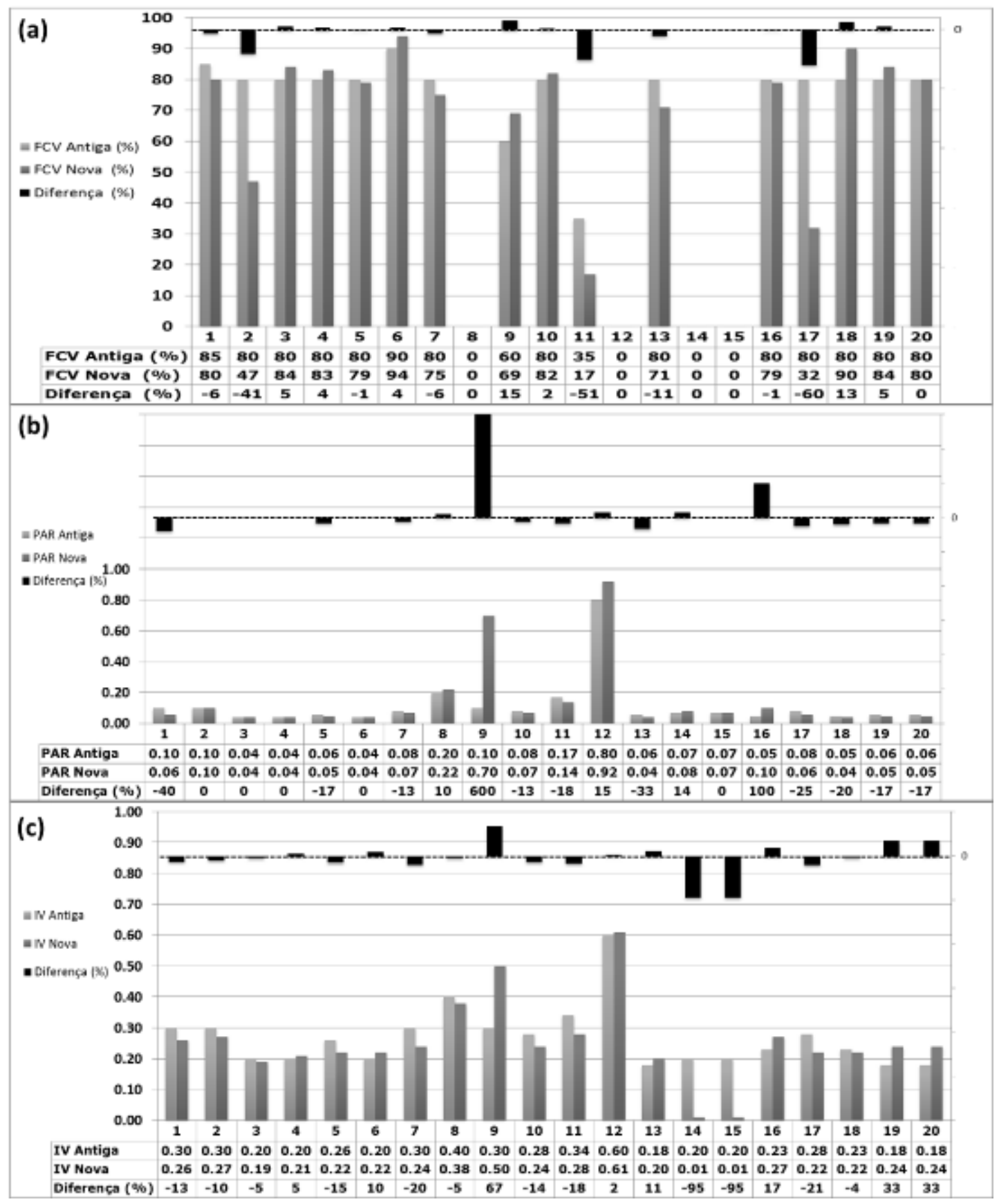

Figura 4. (a) Valores de FCV antigos e atualizados para as classes de uso e cobertura da terra utilizadas pelo modelo de superfície BATS; (b) Valores de PAR antigos e atualizados utilizados nas simulações numéricas; (c) Valores de Reflectância no IV antigos e atualizados.

A alteração dos valores de reflectância PAR e IV foram realizadas a partir dos valores calculados com base nos dados do sensor MODIS/TERRA. Em relação aos valores de FCV (estimados a partir do NDVI), obtidos a partir de composições mensais, os valores de reflectância PAR e no infravermelho solar, provenientes do produto MCD43C3, possuem resolução temporal de 16 dias. Desta forma, é comum encontrar regiões com nuvens, tal característica dificulta o processo de aquisição. Desta forma, para evitar contabilizar estes pixels na estimativa dos valores PAR e IV para cada classe de uso e cobertura da terra adotada 
pelo BATS, os valores referentes à esta variável foram determinados a partir da maior frequência em cada classe (moda realizada para 22 imagens com menor distribuição de nuvens). Entre as diferenças encontradasnos valores padrão do modelo e os estimados a partir do sensor MODIS, podem-se citar áreas com predominância agrícola, região pantanosa, água interior, oceano e vegetação arbustiva perene.

Diferenças na simulação trimestral e decadal no REGCM4 devido às variações dos parâmetros físicos adotados

Com o intuito de verificar a variação ocasionada pela alteração dos parâmetros físicos adotados pelo BATS e pela atualização do uso e cobertura da terra, realizaram-se quatro simulações: duas compreendendo o ano de 2007 (na qual o uso do solo foi atualizado a partir de dados disponíveis, Figura 5) e duas de 10 anos (2000 a 2009), em que cada par de simulações corresponde ao modelo em suas configurações padrão e a partir das alterações citadas acima.
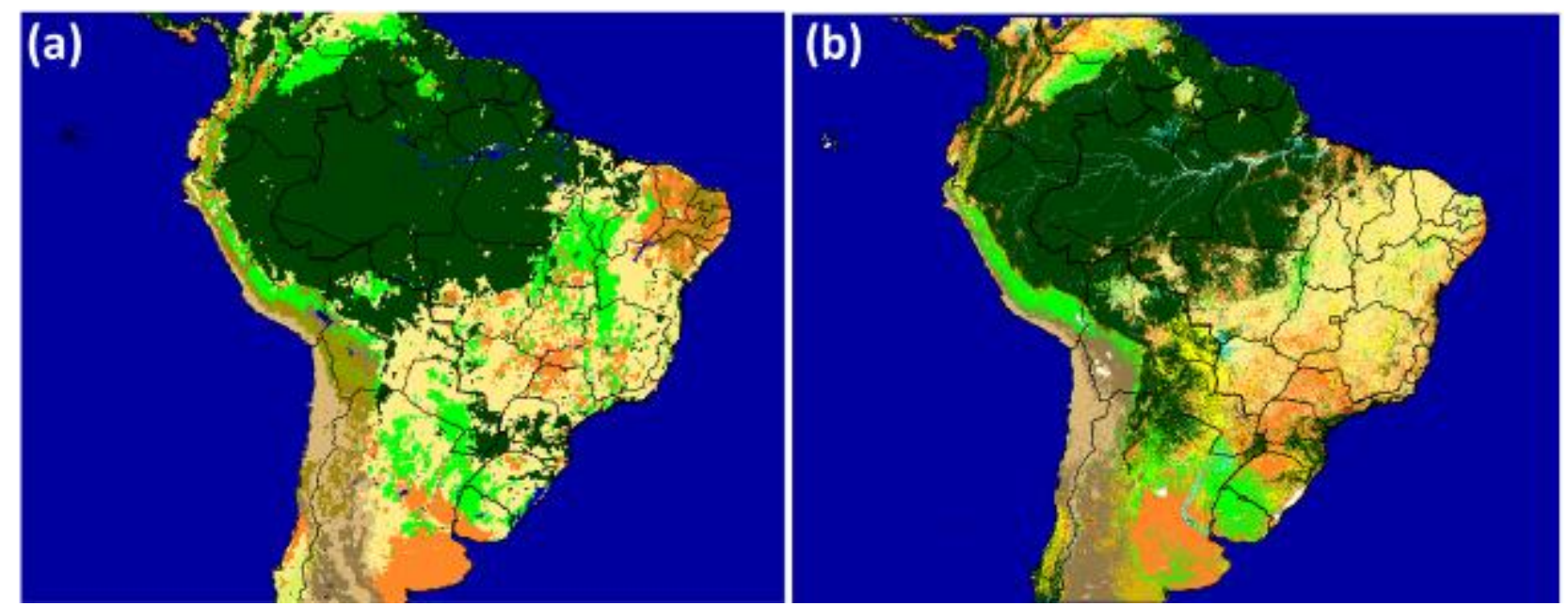

Figura 5. (a) Uso e cobertura da terra utilizado pelo modelo RegCM4; (b) Mapa de uso e cobertura da terra atualizado.

FONTE: Adaptado de Pereira et al. (2012).

As diferenças trimestrais nos valores de umidade relativa do ar provenientes das simulações realizadas no RegCM4 podem ser visualizadas na Figura 6. Nesta, os valores em azul descrevem regiões em que houve um aumento na umidade relativa do ar devido às alterações dos parâmetros físicos utilizados pelo BATS e, consequentemente, tons em amarelo/vermelho representam a redução desta. A umidade relativa do ar é uma variável meteorológica que descreve a proximidade de saturação do ar, ou seja, ela representa a relação entre a quantidade de moléculas de água presentes em determinado volume de ar e a capacidade total de vapor que este volume poderia conter (pressão parcial de vapor pela pressão de saturação a uma mesma temperatura).

A partir das alterações no modelo de superfície BATS, percebe-se no primeiro trimestre de 2007 (Figura 6a) um aumento considerável na umidade relativa do ar no Paraguai e Argentina, na Região Nordeste do Brasil, no Pará e no Amapá, sendo que nestas áreas a diferença entre as duas simulações podem alcançar $12 \%$. Ainda, nota-se uma diminuição desta variável para os Estados do Mato Grosso e Amazonas e para a região dos Andes entre a Argentina, Bolívia, Peru e Chile, com valores entre $-6 \%$ a $-15 \%$. As diferenças para os meses de ABR/MAI/JUN apresentam o mesmo padrão espacial de mudanças, porém, com uma atenuação nos valores em relação à JAN/FEV/MAR. Na estação seca (para o Brasil Central), percebe-se uma diminuição na umidade relativa do ar para o Estado do Amazonas (de $-3 \%$ a $9 \%$ ) e a 
permanência de valores positivos próximos ao Paraguai e à Região Sul do Brasil, com valores entre $3 \%$ a $9 \%$. Todavia, o trimestre que compreende os meses de OUT/NOV/DEZ apresentou um comportamento diferente dos encontrados anteriormente. Nestes meses, a alteração das propriedades físicas no modelo de superfície BATS proporcionaram uma redução da umidade relativa do ar em praticamente todo o Brasil, com exceção da porção norte do Brasil (próxima à linha do equador).

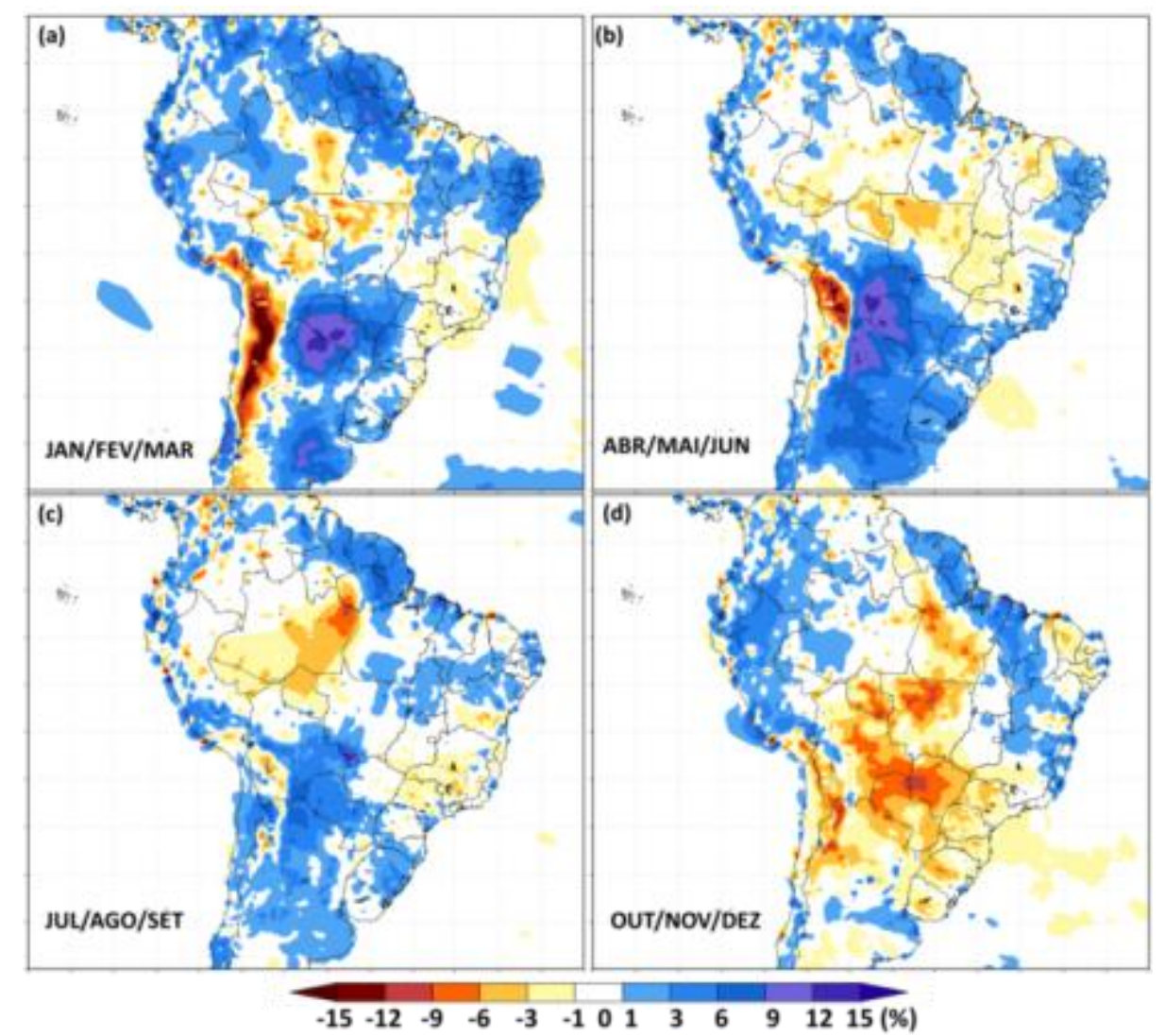

Figura 6.Diferença nas estimativas trimestrais da umidade relativa do ar estimada a partir da simulação da variação dos parâmetros físicos (FCV, IAF, REF) e as condições originais do modelo de superfície BATS para 2007: a) JAN/FEV/MAR; b) ABR/MAI/JUN; c) JUL/AGO/SET; e d) OUT/NOV/DEZ.

A Figura 7 exibe as alterações trimestrais ocorridas na umidade relativa do ar para 10 anos (2000 a 2009). Similar às variações trimestrais de 2007, percebe-se que a diferença entre as simulações exibe as mesmas alterações, com exceção do último trimestre (OUT/NOV/DEZ, Figura 7d). Em geral, percebe-se que o desmatamento da Floresta Amazônica ocasiona a redução média da umidade relativa do ar em até $9 \%$ (Figuras $7 a$ e $7 d$ ), do mesmo modo, a inclusão da Floresta Estacional Decidual no Paraguai no mapa de uso e cobertura da terra utilizado pelo RegCM4, ocasiona um aumento da umidade relativa de aproximadamente $6 \%$. Ainda, o aumento das áreas agrícolas na Região Sudeste e Centro-Oeste, proporciona uma elevação de até $6 \%$ nesta variável (principalmente na estação seca). Entre as principais causas das alterações na umidade relativa do ar, pode-se citar o aumento/diminuição da evapotranspiração e da precipitação em determinadas áreas e as modificações no balanço de radiação.

As Figuras $7 \mathrm{e}, 7 \mathrm{f}$ e $7 \mathrm{~g}$ mostram a média da umidade relativa do ar para as simulações de 10 anos realizadas no RegCM4 (com alteração dos parâmetros físicos e com as condições padrão) e a climatologia disponibilizada pelo INMET/CPTEC para o período de 1961 a 2001, respectivamente. Nas figuras é possível verificar que os menores valores referentes à média da umidade relativa do ar localizam-se no interior do Brasil, com valores inferiores a $70 \%$. Ainda, os maiores valores localizam-se na Bacia Amazônica, com valores superiores a 85\%. Embora os valores climatológicos da umidade relativa do ar para o Brasil (Figura 7g) 
representem os valores médios entre 1961 e 2001, estes indicam o padrão da distribuição espacial desta variável para o Brasil. Desta forma, em relação à espacialização da umidade relativa do ar, percebe-se uma boa concordância entre os dados simulados no RegCM4 (Figuras 7e e 7f)e os dados provenientes das estações meteorológicas.

Porém, pode-se verificar que em geral os valores estimados apresentam-se de $5-10 \%$ abaixo dos dados coletados, com exceção da região litorânea entre Santa Catarina e São Paulo e o extremo oeste da região Amazônica, onde os valores estão próximos aos valores climatológicos. Entre as principais características encontradas pode-se citar: I) os baixos valores de umidade relativa do ar no Estado do Pará, que apresentam valores entre $20-30 \%$ abaixo do esperado; II) as subestimativas para grande parte da região litorânea do Brasil, principalmente para os Estados da Bahia, Rio de Janeiro, Espirito Santo e Rio Grande do Sul; III) a boa concordância nas estimativas para o Estado de Santa Catarina e Paraná; e IV) as subestimativas para o bioma Cerrado e Pantanal.

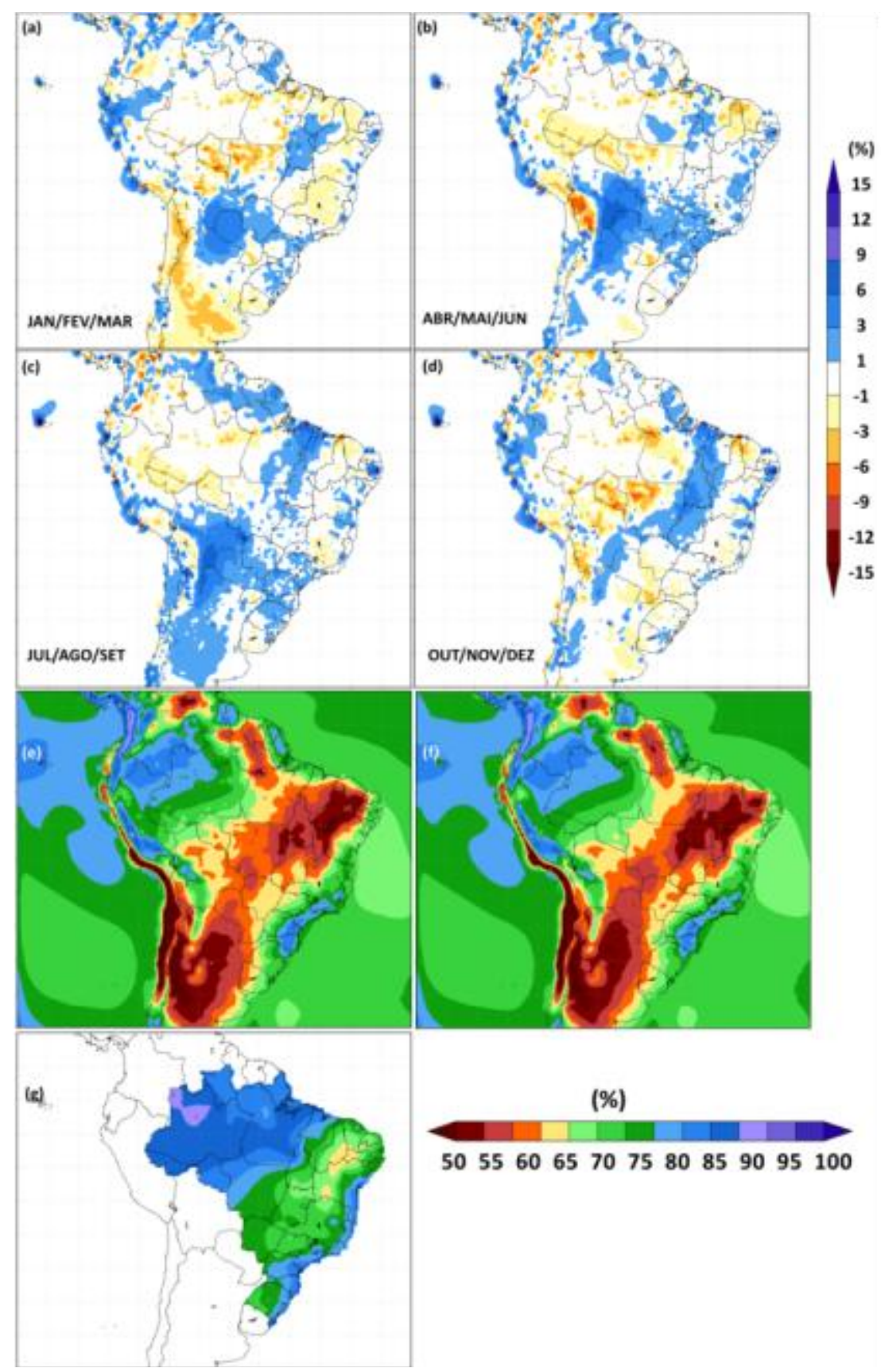

Figura 7. Diferença nas estimativas trimestrais da umidade relativa do ar resultantes das simulações para o período de 2000 a 2009, para: a) JAN/FEV/MAR; b) ABR/MAI/JUN; c) JUL/AGO/SET; e d) OUT/NOV/DEZ; média anual da umidade relativa do ar para as simulações no RegCM4 (2000 a 2009 ) e climatologia estimada pelos dados do INMET/CPTEC (1961 a 2001), (e), (f) e (g), respectivamente. 
Variações na evapotranspiração, precipitação, temperatura do ar e radiação: estudos de caso.

O uso e cobertura da terra é uma componente fundamental nas simulações numéricas de tempo e clima. Consequentemente, a representação desta variável em modelos climáticos regionais, assim como, suas características físico-químicas e biológicas, é de fundamental importância para a análise das interações entre a radiação eletromagnética solar e a superfície terrestre, para os estudos das trocas de energia entre a biosfera-atmosfera, entre outros. A Figura 8 exibe as áreas de uso e cobertura da terra que foram alteradas (em marrom) ou permaneceram idênticas (em branco) a partir da atualização do mapa do GLCC (1992) pelo mapa proveniente do sensor MODIS para o ano de 2007.

Para verificar o impacto da substituição dos usos e coberturas da terra na evapotranspiração, precipitação, temperatura a dois metros e radiação solar incidente (indicativo da cobertura de nuvens) foram selecionados seis pontos na área de estudo relacionados com: 1) Arco do desflorestamento (substituição de área de Floresta Amazônica por áreas agrícolas e de pecuária); 2) Interior do Brasil (substituição de vegetação herbácea para mosaico de Floresta/pastagem); 3) Nordeste do Brasil (substituição de áreas de agricultura por vegetação arbustiva decidual); 4) Venezuela (substituição de vegetação herbácea por áreas de agricultura e mosaico de Floresta/pastagem); 5) Paraguai (substituição de gramíneas por Floresta Estacional Semidecidual); e 6) Argentina (substituição de mosaico de Floresta/pastagem por áreas agrícolas e de pecuária).

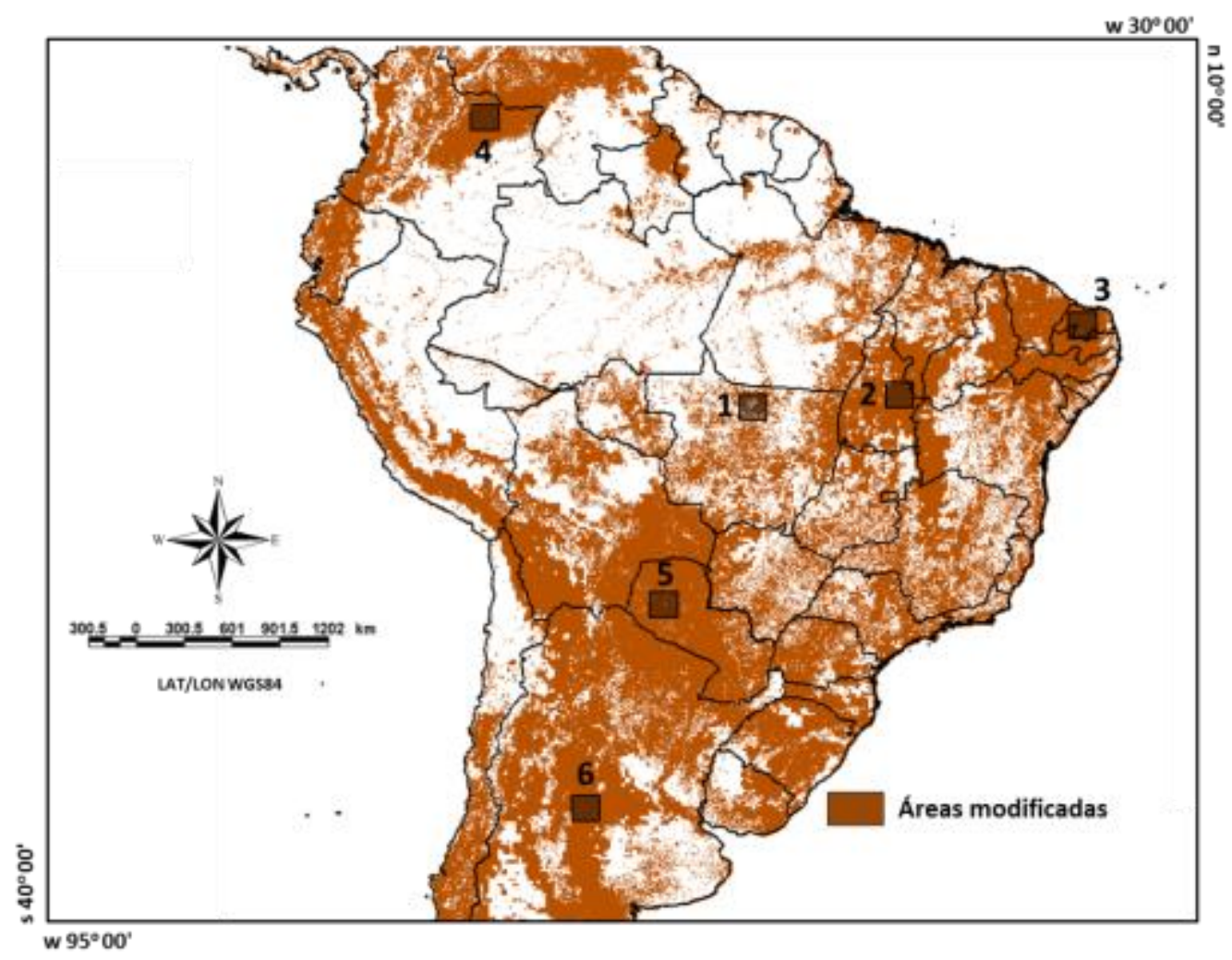

Figura 8. Áreas de uso e cobertura da terra (em marrom) que foram substituídas por outros usos relativos ao mapa do MCD12 (2007) quando comparados ao mapa original (GLCC, 1992) implementado no modelo RegCM4 e utilizado pelo esquema de superfície BATS; localização dos seis pontos selecionados para estudos de caso.

Para cada ponto indicado realizou-se uma média do pixel central e dos oito pixels vizinhos, totalizando uma área de $22.500 \mathrm{~km}^{2}(150 \times 150 \mathrm{~km})$, como indicado na Figura 8 (acima). A Figura 9 mostra a variação temporal para 10 anos (Jan/2000 a Jan/2010) para o ponto 1 correspondente à substituição de área de Floresta Amazônica por áreas agrícolas e de pecuária. A substituição de áreas de floresta ombrófila densa por pastagens e áreas agrícolas 
ocasiona a diminuição da evapotranspiração, principalmente pela redução da transpiração vegetal nos meses de maior atividade convectiva. Para a área analisada, é evidente a diminuição em até $1,5 \mathrm{~mm} \cdot \mathrm{dia}^{-1}$, ou seja, $45 \mathrm{~mm}$ por mês. As comparações mensais da precipitação total (incluído todos os processos de formação de precipitação) para o ponto 1 indicam que, de um modo geral, há uma tendência de redução no volume de chuvas, principalmente para os primeiros oito anos para o período convectivo. Por outro lado, como demonstrado nas simulações, estes valores simulados encontram-se superestimados em relação aos dados do TRMM (em verde). A diminuição da evapotranspiração e precipitação influenciam diretamente a formação de nuvens. A evapotranspiração e a precipitação são estimadas a partir do balanço de radiação e este é função do saldo de radiação solar e termal incidente, os quais estão relacionados com o albedo, irradiância solar e com a temperatura da superfície. A irradiância solar incidente no topo da atmosfera não varia entre as simulações, portanto a diferença na incidência da radiação solar na superfície está diretamente relacionada com a formação de nuvens. Desta forma, se a incidência de radiação solar na superfície diminuir entre as simulações, constata-se um aumento na formação de nuvens, ao contrário (aumento entre as simulações), pode-se afirmar que houve uma diminuição na quantidade de nuvens. Embora que sutilmente, percebe-se uma tendência no aumento da quantidade de nuvens na região de influência do desflorestamento devido principalmente ao aumento da temperatura da superfície. Em geral, o desflorestamento nestas áreas ocasiona um aumento de até $2^{\circ} \mathrm{C}$ na temperatura do ar a dois metros, como visualizado no gráfico da Figura 9.

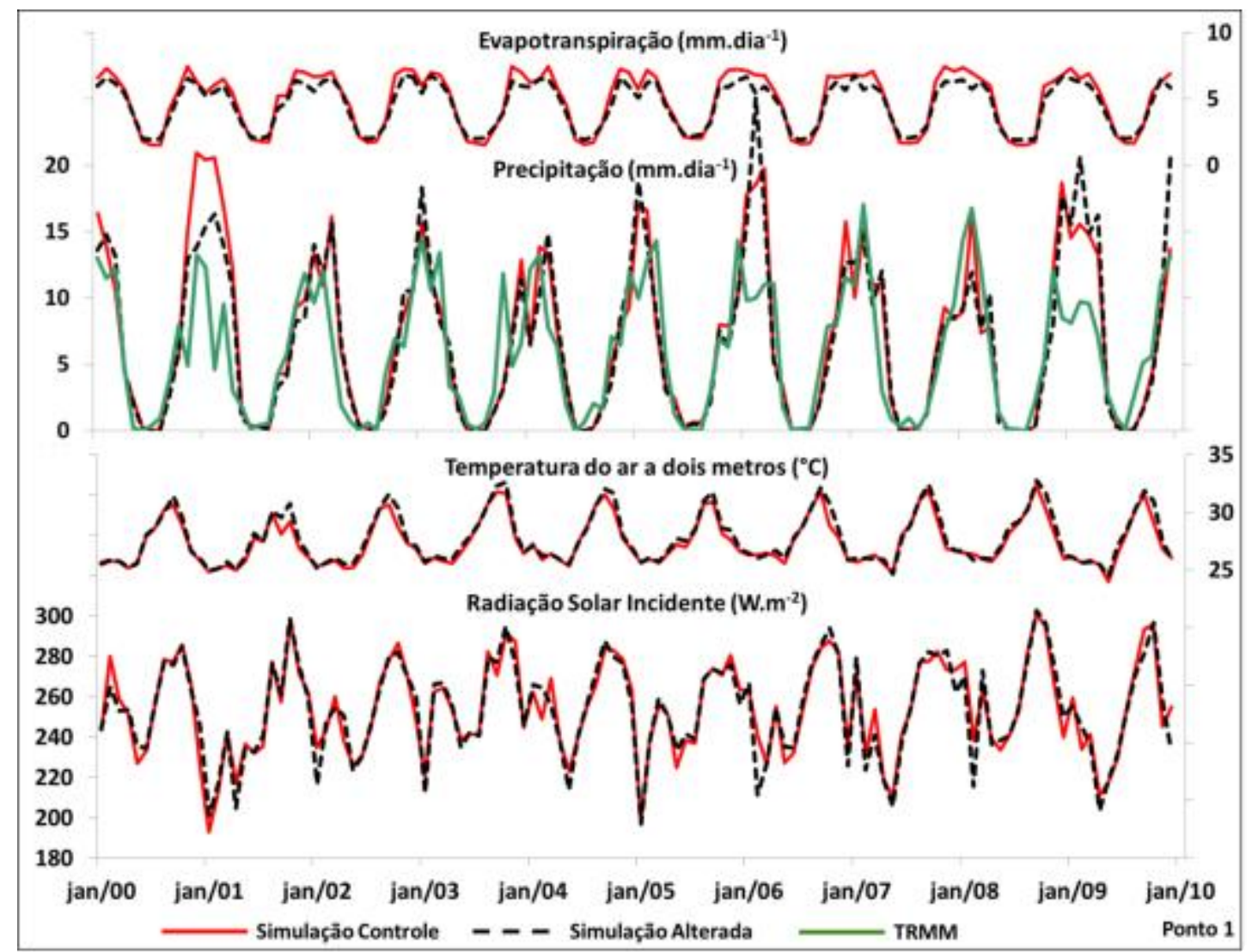

Figura 9. Valores mensais de evapotranspiração $\left(\mathrm{mm} \cdot \mathrm{dia}^{-1}\right)$, precipitação $(\mathrm{mm})$, temperatura a dois metros de altitude $\left({ }^{\circ} \mathrm{C}\right)$ e radiação solar incidente $\left(\mathrm{W} . \mathrm{m}^{-2}\right.$ ) para o ponto 1, de Jan/2000 a Jan/2010, referente à substituição de áreas de floresta ombrófila densa por pastagem e agricultura para a simulação de controle (em vermelho) e para a simulação com alteração dos parâmetros físicos e do uso e cobertura da terra (em preto, linha tracejada).

A Figura 10 exibe a variação temporal para 10 anos (Jan/2000 a Jan/2010) para o ponto 2 localizado no Estado do Tocantins. Neste ponto, ocorreu a mudança da vegetação 
herbácea/gramíneas por áreas de Floresta/pastagem. Esta alteração no uso e cobertura da terra ocasiona um aumento na evapotranspiração diária com valores mensais superiores a 40 $\mathrm{mm}\left(1,3 \mathrm{~mm} \cdot \mathrm{dia}^{-1}\right)$. Além disso, a substituição de áreas de vegetação herbácea por mosaico de Floresta e pastagem ocasiona um aumento na precipitação devido principalmente à disponibilidade de vapor d'água para os processos convectivos. Consequentemente, há um aumento da quantidade de nuvens e um aumento da precipitação, verificando-se uma diminuição da radiação solar incidente na área. Em relação à temperatura do ar a dois metros, percebe-se uma variação muito pequena, ou seja, a alteração do uso e cobertura da terra e dos parâmetros físicos não ocasiona uma mudança significativa nesta variável. Ainda, percebese que as alterações nas propriedades físico-químicas e biológicas permite que o modelo estime a precipitação mais adequadamente, com exceção do ano de 2001, na qual os valores estimados foram aproximadamente duas vezes maiores que os observados pelo TRMM.

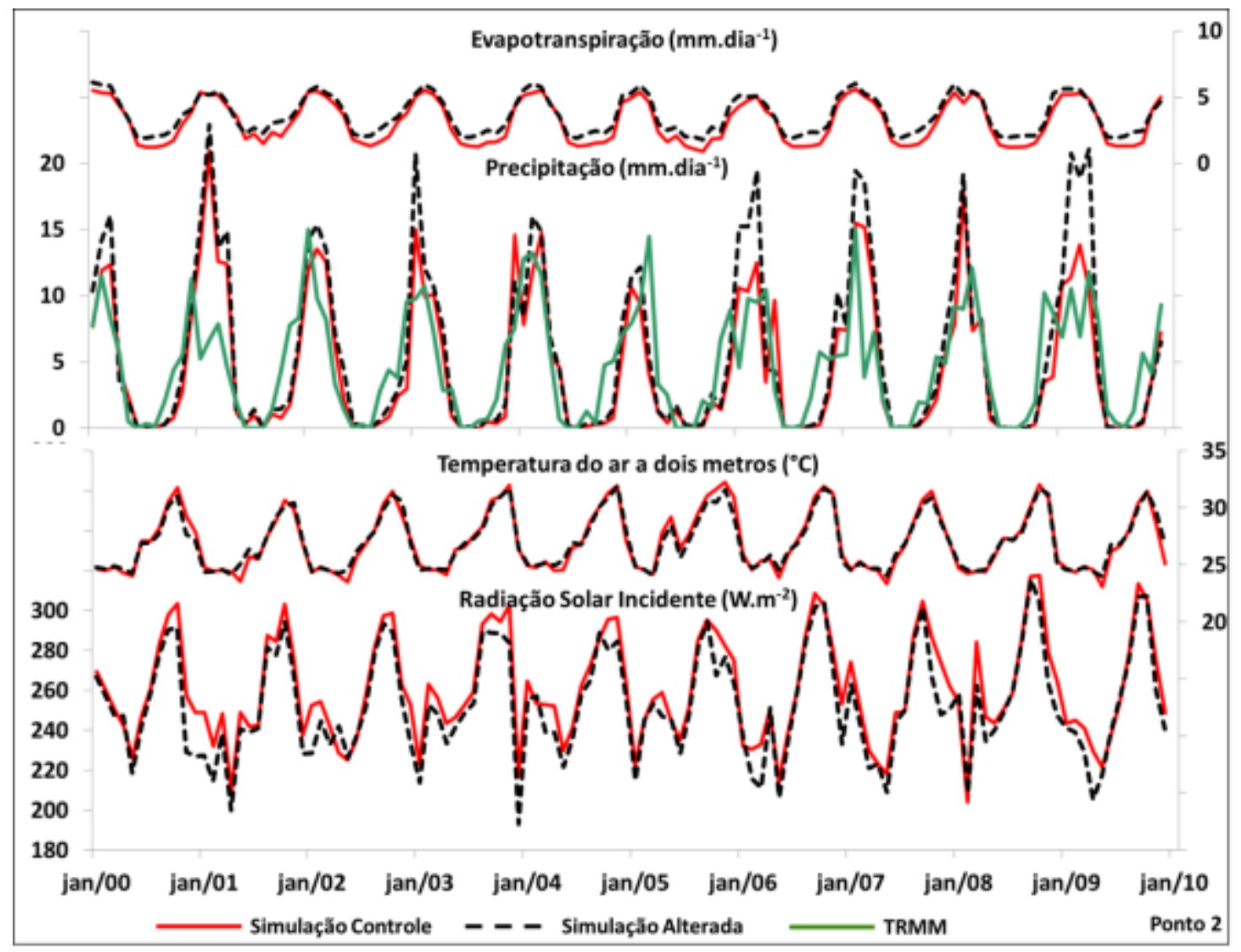

Figura 10. Valores mensais de evapotranspiração $\left(\mathrm{mm} \cdot \mathrm{dia}^{-1}\right)$, precipitação $(\mathrm{mm})$, temperatura a dois metros de altitude $\left({ }^{\circ} \mathrm{C}\right)$ e radiação solar incidente $\left(\mathrm{W} . \mathrm{m}^{-2}\right)$ para o ponto 2, de Jan/2000 a Jan/2010, referente à substituição de vegetação herbácea para mosaico de Floresta/pastagem para a simulação de controle (em vermelho) e para a simulação com alteração dos parâmetros físicos e do uso e cobertura da terra (em preto, linha tracejada).

A Figura 11 mostra as alterações ocorridas na evapotranspiração, na precipitação, na temperatura a dois metros de altitude e na radiação solar incidente para as simulações entre Janeiro de 2000 e Janeiro de 2010 para o ponto 3, localizado no interior da Região Nordeste do Brasil. Neste ponto, áreas agrícolas deram lugar a vegetação natural da região (vegetação arbustiva decidual), corrigindo o uso e cobertura da terra utilizado pelo BATS. O ponto 3 localiza-se numa área árida com baixa evapotranspiração diária, com exceção do período chuvoso (entre outubro e fevereiro). A alteração do uso e cobertura da terra e dos parâmetros físicos ocasionou um aumento da evapotranspiração em alguns anos, porém, percebe-se pouca diferença entre as simulações. Este mesmo padrão é visualizado para a precipitação e para a temperatura do ar a dois metros. Entretanto, percebe-se um aumento na quantidade de 
nuvens (associada à diminuição da radiação solar incidente), principalmente no período chuvoso. Ressalta-se que em comparação com os dados do TRMM, os valores de precipitação estimados pelo RegCM4 encontram-se muito abaixo dos estimados. Em alguns casos, como o ano de 2002 e 2004, percebe-se que o modelo ocasiona um atraso do ciclo hidrológico em aproximadamente três meses, ainda, em 2006 e 2007 os valores estimados pelo RegCM4 estão subestimados em aproximadamente três vezes.

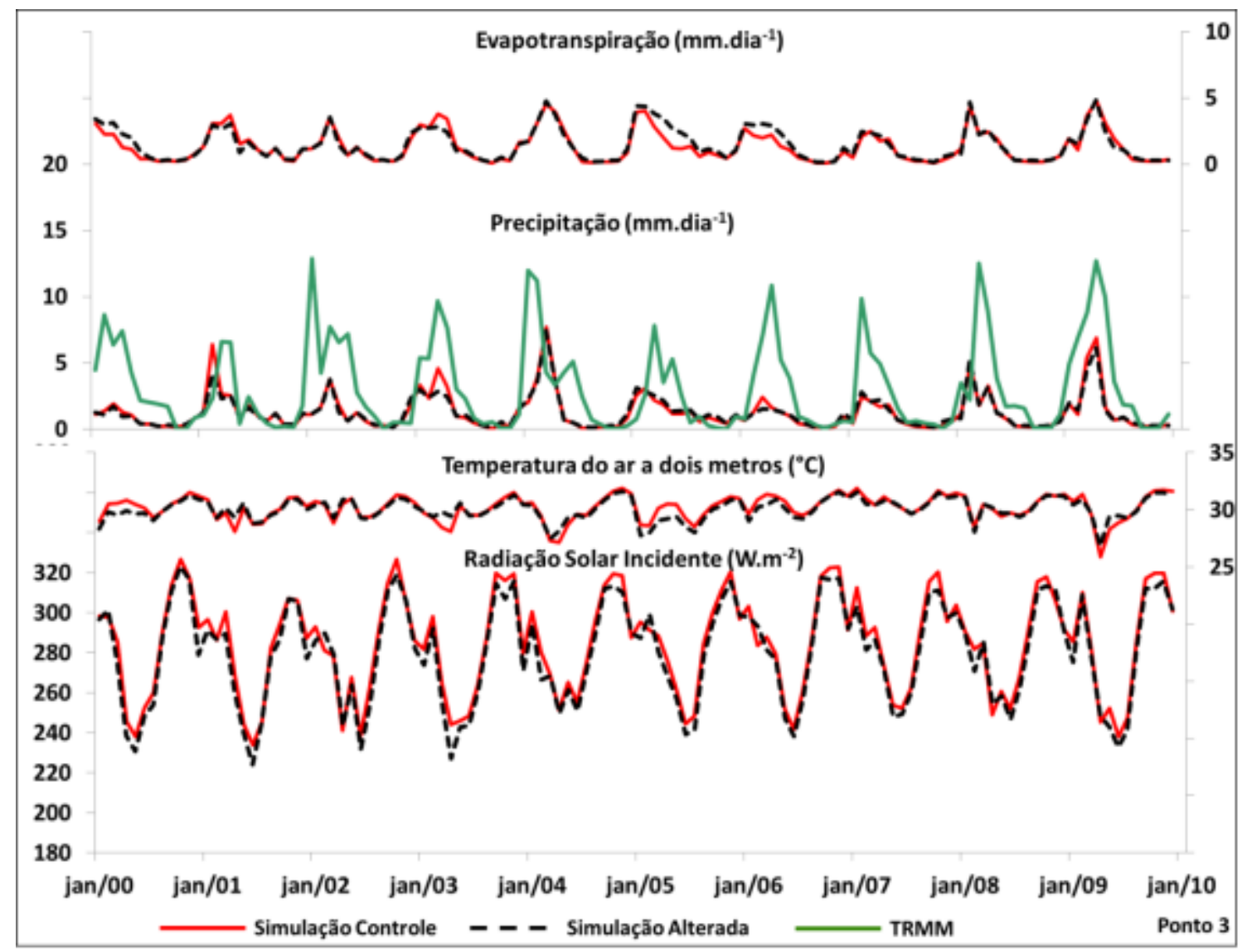

Figura 11. Valores mensais de evapotranspiração $\left(\mathrm{mm}^{\mathrm{d}} \mathrm{dia}^{-1}\right)$, precipitação $(\mathrm{mm})$, temperatura a dois metros de altitude $\left({ }^{\circ} \mathrm{C}\right)$ e radiação solar incidente (W.m ${ }^{-2}$ ) para o ponto 3, de Jan/2000 a Jan/2010, referente à substituição de áreas de agricultura por vegetação arbustiva decidual para a simulação de controle (em vermelho) e para a simulação com alteração dos parâmetros físicos e do uso e cobertura da terra (em preto, linha tracejada).

A Figura 12 mostra os resultados das simulações para uma região na Venezuela (Hemisfério Norte) em que áreas de vegetação herbácea foram substituídas por áreas de agricultura e mosaico de Floresta/pastagem. Entre as principais variações decorrentes desta modificação, pode-se citar a diminuição da precipitação nos meses mais chuvosos e aumento na quantidade de nebulosidade nos meses mais chuvosos. Em alguns anos, os valores de precipitação são superestimados pelo modelo RegCM4, principalmente na época seca. Ressalta-se que a precipitação sobre a região amazônica e próximas a zona de convergência intertropical (ZCIT) são de difícil assimilação e modelagem, causando erros consideráveis nas simulações numéricas. Ainda, constata-se que a evapotranspiração e a temperatura do ar a dois metros permanecem praticamente constantes entre ambas as simulações, indicando que a alteração destes usos e cobertura da terra pouco influenciou nestas variáveis meteorológicas, ou seja, a mudança do uso e cobertura da terra correspondente à vegetação herbácea por áreas de agricultura e mosaico de Floresta/Pastagem não altera consideravelmente as propriedades da superfície. 


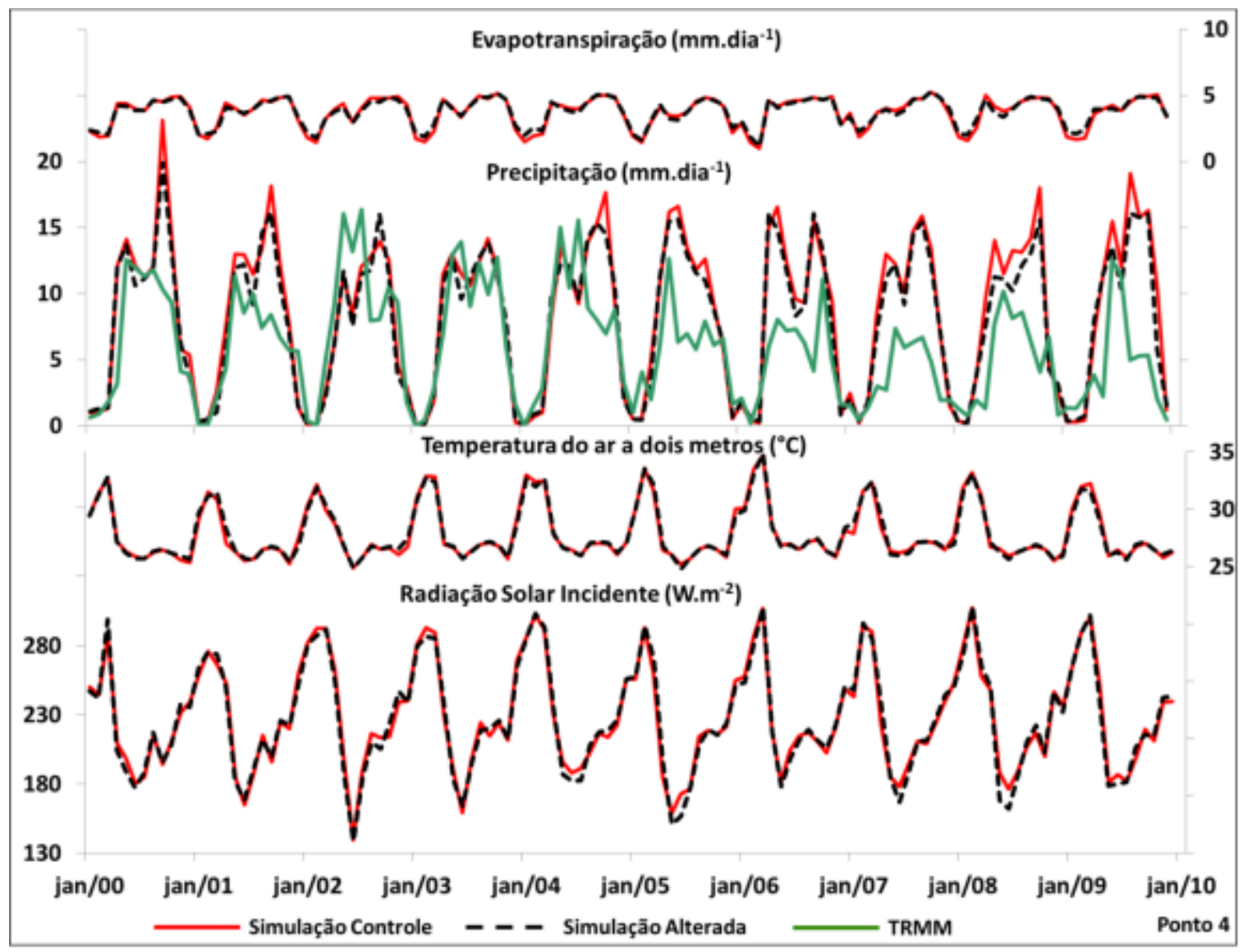

Figura 12. Valores mensais de evapotranspiração $\left(\mathrm{mm}^{\mathrm{d}} \mathrm{dia}^{-1}\right)$, precipitação $(\mathrm{mm})$, temperatura a dois metros de altitude $\left({ }^{\circ} \mathrm{C}\right)$ e radiação solar incidente $\left(\mathrm{W} . \mathrm{m}^{-2}\right.$ ) para o ponto 4, de Jan/2000 a Jan/2010, referente à substituição de vegetação herbácea por áreas de agricultura e mosaico de Floresta/pastagem para a simulação de controle (em vermelho) e para a simulação com alteração dos parâmetros físicos e do uso e cobertura da terra (em preto, linha tracejada).

A Figura 13 exibe a variação temporal para 10 anos (Jan/2000 a Jan/2010) para o ponto 5 localizado no Paraguai. Neste ponto ocorreu a mudança de gramíneas por Floresta Estacional Semidecidual, para corrigir os erros de classificação no produto do GLCC. Uma possível aplicação desta simulação diz respeito à áreas de regeneração e seus impactos no clima. Em geral, esta alteração no uso e cobertura da terra ocasiona um aumento na evapotranspiração diária com valores mensais superiores a $30 \mathrm{~mm}\left(1,0 \mathrm{~mm}^{-1 i a^{-1}}\right)$. Além disso, a substituição de gramíneas por espécies arbóreas ocasiona um aumento significativo na precipitação devido principalmente à disponibilidade de vapor d'água para os processos convectivos. Em alguns anos (2005 e 2007) este aumento pode alcançar $200 \mathrm{~mm}$ em meses específicos. Consequentemente, o aumento da precipitação está associado à maior quantidade de nuvens que pode ser identificada pela diminuição da radiação solar incidente, principalmente na estação chuvosa (verão do Hemisfério Sul). Em relação à temperatura do ar a dois metros, percebe-se a tendência de diminuição desta variável em todos os meses, o que pode ser resultado da maior disponibilidade de água no dossel. 


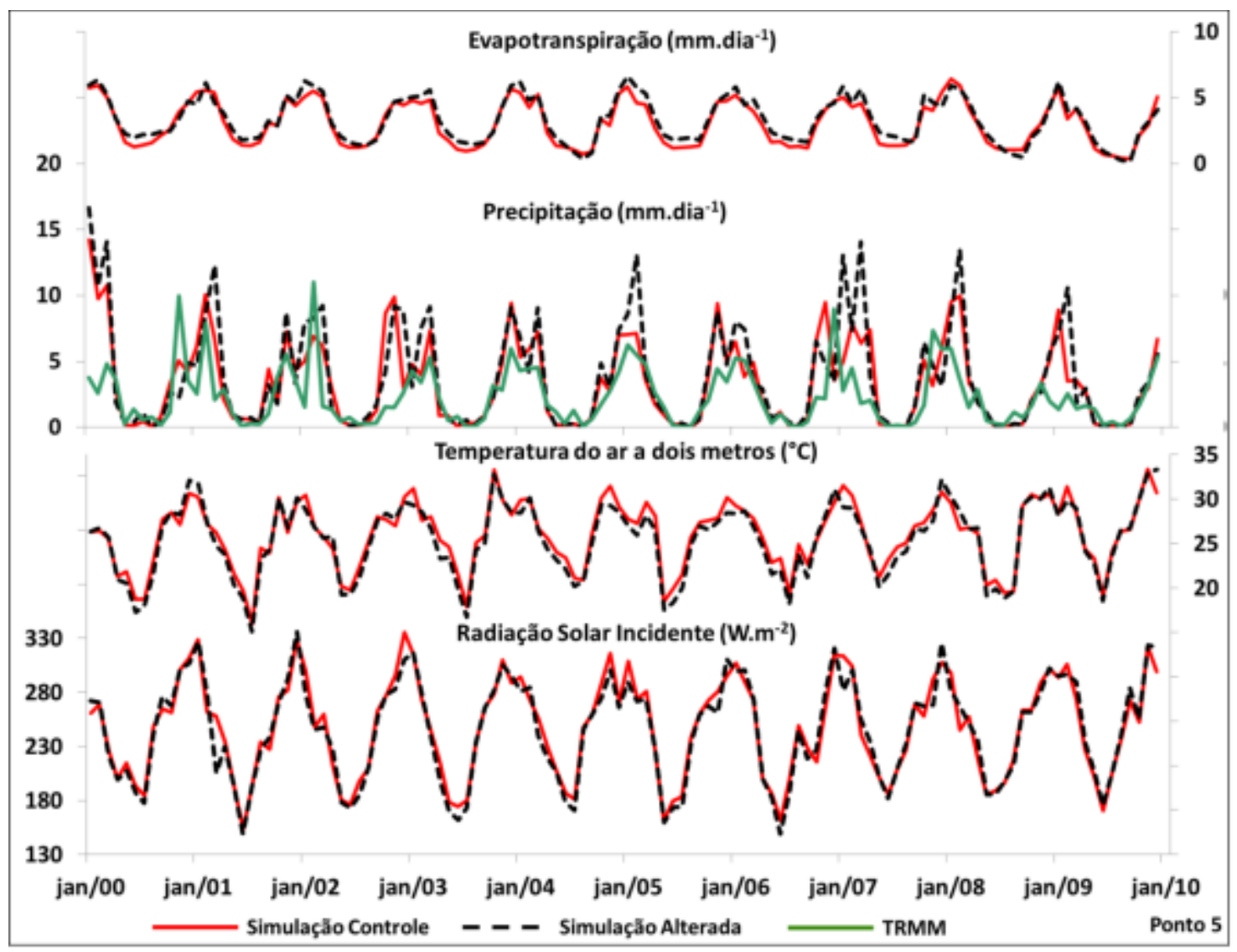

Figura 13. Valores mensais de evapotranspiração $\left(\mathrm{mm} \cdot \mathrm{dia}^{-1}\right)$, precipitação $(\mathrm{mm})$, temperatura a dois metros de altitude $\left({ }^{\circ} \mathrm{C}\right)$ e radiação solar incidente $\left(\mathrm{W} \cdot \mathrm{m}^{-2}\right.$ ) para o ponto 5, de Jan/2000 a Jan/2010, referente à substituição de gramíneas por Floresta Estacional Semidecidual para a simulação de controle (em vermelho) e para a simulação com alteração dos parâmetros físicos e do uso e cobertura da terra (em preto, linha tracejada).

A Figura 14 mostra as alterações ocorridas na evapotranspiração, precipitação, temperatura a dois metros de altitude e radiação solar incidente para as simulações entre janeiro de 2000 e janeiro de 2010 para o ponto 6, localizado na bacia do Rio da Prata (Argentina). Neste ponto, ocorreu a substituição de mosaico de Floresta/pastagem por áreas agrícolas e de pecuária. 0 ponto 6 localiza-se numa área com baixa evapotranspiração no período de inverno (julho a setembro), e com seu aumento no período chuvoso (entre outubro e fevereiro). A inserção de áreas agrícolas ocasionou poucas mudanças na estimativa da evapotranspiração quando comparados os resultados das duas simulações. Este mesmo comportamento é detectado na temperatura do ar a dois metros e na radiação solar incidente. Entretanto, percebe-se uma variação mais significativa na precipitação, que diminui principalmente nos meses de inverno, aparentemente seguindo a leve diminuição notada na evapotranspiração neste período. 


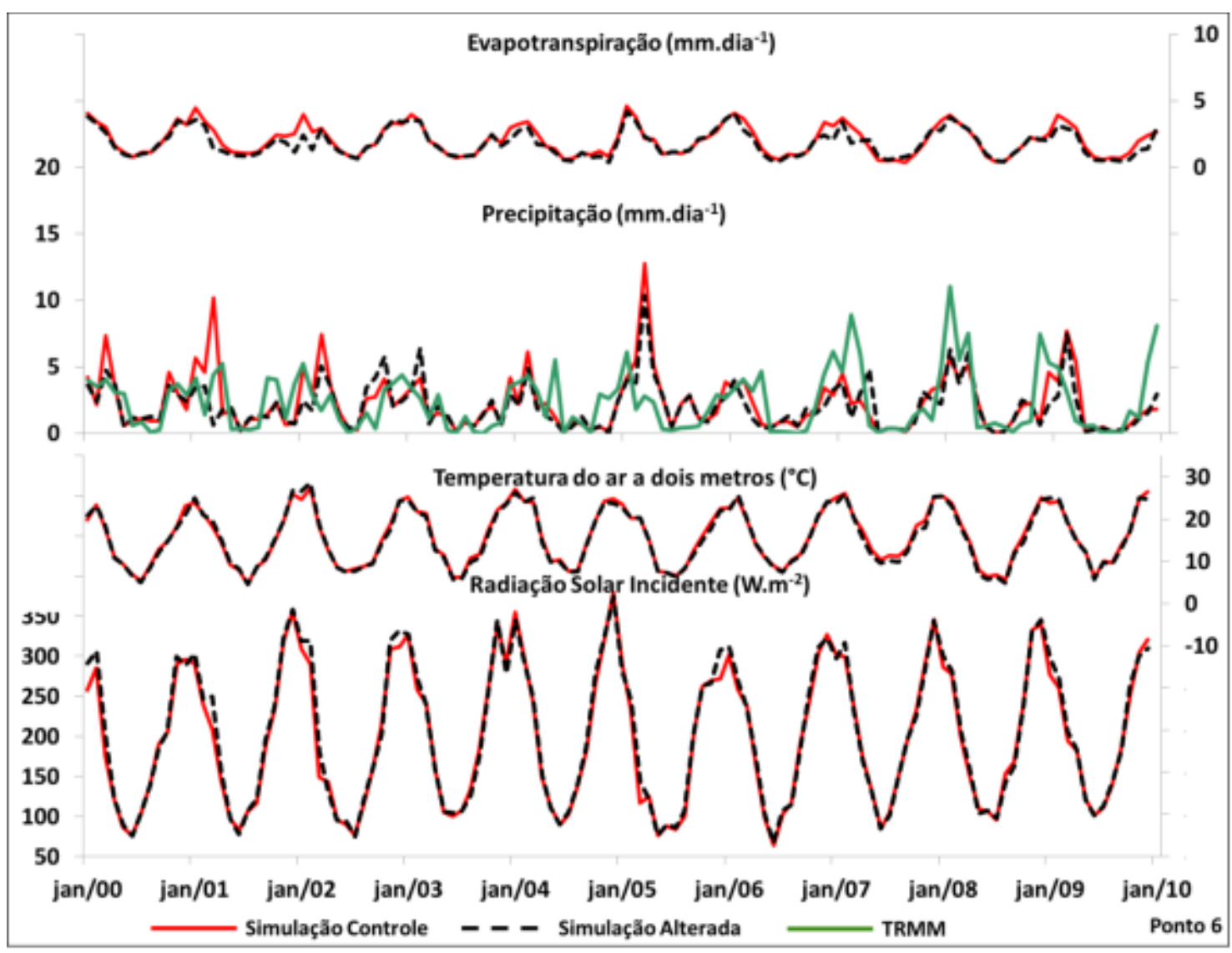

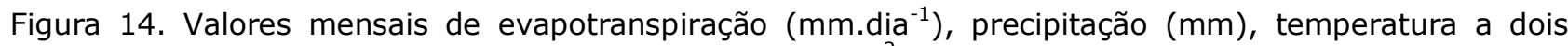
metros de altitude $\left({ }^{\circ} \mathrm{C}\right)$ e radiação solar incidente $\left(\mathrm{W} . \mathrm{m}^{-2}\right.$ ) para o ponto 6, de Jan/2000 a Jan/2010, referente à substituição de mosaico de Floresta/pastagem por áreas agrícolas e de pecuária para a simulação de controle (em vermelho) e para a simulação com alteração dos parâmetros físicos e do uso e cobertura da terra (em preto, linha tracejada).

\section{CONSIDERAÇÕES FINAIS}

Os modelos regionais de previsão do tempo e clima são de fundamental importância nos estudos sobre as interações entre a biosfera e atmosfera, porém, sua eficácia depende, principalmente, de parametrizações realísticas dos processos que envolvem e controlam estas variáveis meteorológicas. Neste estudo, verificou-se o impacto nas simulações numéricas decorrentes de uma melhor representatividade dos mapas de uso e cobertura da terra e suas respectivas características físico-químicas e biológicas.

Neste contexto, os dados anuais e multitemporais de fração máxima de cobertura vegetal, reflectância fotosinteticamente ativa e no infravermelho solar e do índice de área foliar foram inseridos no esquema de superfície BATS e testes de sensibilidades foram realizados para o ano de 2007 e para o período de 2000 a 2009. Consequentemente, simulações decadais distintas (com a alteração dos parâmetros descritos acima e com a configuração padrão do modelo) foram realizadas no modelo RegCM4 para verificar o impacto atmosférico decorrente destas alterações. Entre as principais diferenças encontradas nas variáveis meteorológicas analisadas (umidade relativa do ar, evapotranspiração, precipitação, temperatura do ar a dois metros e radiação solar incidente) decorrentes da atualização das informações referentes à superfície e suas propriedades, pode-se citar a região do arco do desmatamento (divisa de Mato Grosso com Pará e Amazonas), região noroeste do Paraguai e na região da Bacia do Rio da Prata na Argentina e Região Nordeste do Brasil. As principais alterações decorrem da substituição de áreas com Floresta Ombrófila Densa por áreas de pastagem e agricultura. 


\section{AGRADECIMENTOS}

À Fundação de Amparo à Pesquisa do Estado de São Paulo (FAPESP) pelo apoio (2010/07083-0).

\section{REFERÊNCIAS}

BAEDE, A.P.M.; AHLONSOU, E.; DING, Y.; SCHIMEL, D. The Climate System: An Overview. In Houghton, J. T. et al. (eds.), Climate Change 2001: The Scientific Basis. Cambridge University Press, Cambridge, UK, p. 85-98, 2001.

CARLSON, T. N.; RIPLEY, D. A.On the relation between NDVI, fractional vegetation cover, and leaf area index.Remote Sensing of Environment, v. 62, p. 241-252, 1997.

FAO, 2002.World agriculture towards 2015/30. Summary report. ISBN: 9251047618 FAO, Rome.

GCOS.Systematic Observation Requirements for Satellite-based Products for Climate, vol. 107. GCOS, 90 pp, 2006.

ISIDOROV, V.A.; ZENKEVICH, I.G.; IOFFE, B.V. Volatile organic compounds in the atmosphere of forests.Atmospheric Environment, v. 19, n. 1, p. 1-8, 1985.

MEARNS, L.O.; GIORGI, F.; MCDANIEL, L.; SHIELDS, C. Analysis of daily variability of precipitation in a nested regional climate model: comparison with observations and doubled $\mathrm{CO}_{2}$ results. Global and Planetary Change, v. 10, n. 1-4, p. 55-78, 1995.

MEYER, W.B.; TURNER, B.L. Changes in Land Use and Land Cover: A Global Perspective. Cambridge: Cambridge University Press, 1994.

MOLDERS, N.; RUHAAK, W. On the impact of explicitly predicted runoff on the simulated atmospheric response to small-scale land-use changes--an integrated modeling approach. Atmospheric Research, v. 63, n. 1-2, p. 3-38, 2002.

NIYOGI D.; MAHMOOD, R.; ADEGOKE, J.O. Land-use/land-cover change and its impacts on weather and climate.Boundary-Layer Meteorology, v. 133, p. 297-298, 2009.

PEREIRA, G.; SILVA, M.E.S.; MORAES, E.C. Análise da variabilidade trimestral e decadal ocasionadas pela alteração dos parâmetros físicos da superfície. Revista Formação Online, v. 2, p. 51-79, 2012.

PEREIRA, G.; SILVA, M.E.S.; MORAES, E.C. Impactos na simulação atmosférica devido à mudança do uso e cobertura da terra na América do Sul. Boletim de Geografia (Online), v. 31 , p. 85-100, 2013.

RICHARDS, J.F. Land transformation, In: Turner II B.L. et al. (eds.), The Earth as Transformed by Human Action, p. 163-178, Cambridge Univ. Press, New York, 1990.

SILVA, M.E.S.; FRANCHITO, S.H.; RAO, V.B. Effects of amazonian deforestation on climate: a numerical experiment with a coupled biosphere-atmosphere model with soil hydrology. Theoretical and Applied Climatology, v. 85, p. 1-18, 2006.

XIE, Y.; SHA, Z.; YU, M. Remote sensing imagery in vegetation mapping: a review. J. Plant Ecol., v. 1, p. 9-23, 2008. 